\title{
Ultrathin Wood Laminae-Thermoplastic Starch Biodegradable Composites
}

\author{
Andrea Dorigato ${ }^{1, *}$, Martino Negri ${ }^{2}$ and Alessandro Pegoretti ${ }^{1, *}$ \\ ${ }^{1}$ University of Trento, Department of Industrial Engineering and INSTM Research Unit, Via Sommarive 938123 Trento, Italy \\ ${ }^{2}$ Trees \& Timber Institute, CNR IVALSA, I-38010 San Michele all' Adige, Trento, Italy
}

Received August 31, 2017; Accepted October 9, 2017

\begin{abstract}
Novel fully biodegradable thermoplastic composite laminates reinforced with ultrathin wood laminae were prepared through a hot-pressing process by using two different thermoplastic starch (TPS) matrices. The microstructure and physical properties of the resulting unidirectional and bidirectional laminates were studied. The investigated materials presented a complex microstructure, in which the porosity of the wood laminae was almost entirely occluded by the polymer matrix. The mechanical behavior of the laminates was strongly affected by the obtained microstructure, and matrix penetration in wood pores led to biodegradable composites with elastic modulus and tensile strength higher than those of their constituents. Finally, thermal welding and thermoformability tests proved how these materials possess features typical of thermoplastic materials.
\end{abstract}

KEYWORDS: Starch, ultrathin wood laminae, composites, mechanical properties

\section{INTRODUCTION}

The scientific and industrial interest toward polymer matrix composites (PMCs) as possible replacements of more traditional metallic and ceramic materials has constantly increased in the last years [1]. In general, PMCs are characterized by outstanding specific mechanical properties, easy processability and elevated chemical resistance. However, the use of glass, carbon and aramid fibers as reinforcement embedded in polymer matrices has a certain environmental impact when the complete life-cycle analysis of these materials is considered [2]. Moreover, these materials are generally difficult to recycle [3]. In some cases, natural fibers as a replacement for inorganic reinforcements were considered as a possible solution to reduce the environmental impact [4], and in some cases natural fiber reinforced polymers with properties approaching those of conventional composites were developed [5-7]. However, natural fiber-based thermoplastic composites are generally not mechanically recyclable, and the limited thermal stability of natural fillers limits the subsequent recycling or reprocessing possibility of these materials [8].

${ }^{*}$ Corresponding author: andrea.dorigato@unitn.it; alessandro. pegoretti@unitn.it

DOI: 10.7569/JRM.2017.634177
Starch is a completely biodegradable polysaccharide that can be synthesized by numerous plants. From a chemical point of view, starch is a semicrystalline polymer composed of linear amylose and highly branched amylopectin [9]. Nowadays, many basic and applied studies on thermoplastic starch (TPS) as a cheap and abundant natural plastic are being developed, with the aim to reduce the total amount of synthetic plastic waste [10]. Thermoplastic starch (TPS) can be processed like synthetic plastics through extrusion and injection molding. Because of its relatively high hydrophilicity, some researchers tried to modify the starch structure, for example, by acetylation, and the physical properties of the resulting materials were strongly affected by the acetylation degree [11, 12]. In some cases, TPS was blended with other biopolymers to maintain the biodegradability of the final blend. Biopolymer components, such as aliphatic polyesters (polycaprolactone (PCL) or polyhydroxybutyrateco-valerate (PHBV)), have been widely used [13]. In other cases, polymer blends with synthetic polymers, such as polyethylene, led to not fully biodegradable materials. Successful examples of commercial starchbased blends are Mater-Bi ${ }^{\circledR}$ (Novamont, Italy) [14] and Bioplast $^{\circledR}$ (Biotec, Germany) [15].

Wood fibers and their derivatives probably represent the most promising natural reinforcements for the production of fully biodegradable composites [16]. Nowadays, one third of the wood is applied 
for the production of structural materials or in the paper industry, and the remaining part is utilized in the coke production or as fueling material [17]. Wood is generally constituted by a combination of carbon, hydrogen and oxygen to form cellulose (40-50 wt\%), hemicellulose (20 wt\%), lignin (about $35 \mathrm{wt} \%$ ) and limited fractions of pectic substances [18]. Wood is an orthotropic material whose mechanical response strongly depends on the direction of the applied loads [19]. Moreover, wood properties can be influenced by the presence of nodes and defects, and by the environmental conditions (especially by the relative humidity level). In this paper, wood reinforcements obtained from beech plants were chosen, because of their regular morphology and anatomical structure [20].

In the last few years, the industrial interest in wood reinforced composite materials was mainly related to wood plastic composites (WPCs), in which thermoplastic matrices (especially polyethylene (PE), polypropylene (PP), polyvinylchloride (PVC)) were reinforced with short wood fibers or wood flour [21]. They can be processed with the traditional techniques of thermoplastics (i.e., extrusion, injection molding). However, the mechanical performances of these products are considerably lower than that of the structural wood, and the weathering effects due to the environmental conditions and to the fungal activity negatively affect the long-term performances of WPCs [22].

Less attention was devoted to the possibility of preparing thermoplastic composite laminates reinforced with wood laminae. Knowing that the performances of the wood are strongly size-dependent, the comprehension of the correlation between the microstructural features of the reinforcing laminae and the macroscopic properties of the resulting composites is of fundamental importance. In a previous paper of our group [23], ultrathin beech laminae were cut through an innovative liner and used to prepare fully biodegradable laminates with a polyvinyl alcohol (PVOH) matrix [24]. The resulting materials were characterized by a peculiar microstructure, in which the original porosity of the wood laminae was occluded by the polymer matrix infiltration, thus leading to fully biodegradable composites with stiffness and strength values considerably higher than those of their constituents.

On the basis of these considerations, the objective of the present paper is to evaluate the potential of novel thermoplastic starch-based fully biodegradable composites, reinforced with ultrathin wood laminae. The thermo-mechanical behavior of the resulting materials will be evaluated and compared with the properties of the constituents, in order to correlate the obtained results with the microstructural features of the laminates. Particular attention was also devoted to the workability conditions of the prepared materials.

\section{EXPERIMENTAL PART}

\subsection{Materials}

Two kinds of thermoplastic starch-based products were supplied by Novamont (Novara, Italy) in the form of thin sheets (thickness $=35 \mu \mathrm{m}$ ): Mater- $\mathrm{Bi}^{\circledast}$ Cf51b (density $1.19 \mathrm{~g} / \mathrm{cm}^{3}$, melt flow index (MFI) at $190{ }^{\circ} \mathrm{C}$ and $2.16 \mathrm{~kg}=5 \mathrm{~g} / 10 \mathrm{~min}$ ) and Mater-Bi ${ }^{\circledR} \mathrm{Kf0} 2 \mathrm{~b}$ (density $1.18 \mathrm{~g} / \mathrm{cm}^{3}$, melt flow index at $190{ }^{\circ} \mathrm{C}$ and 2.16 $\mathrm{kg}=8.5 \mathrm{~g} / 10 \mathrm{~min})$.

The reinforcing wood laminae were obtained from a beech plant, whose apparent density after conditioning at $23^{\circ} \mathrm{C}$ and relative humidity $(\mathrm{RH})=50 \%$ is about $0.73 \mathrm{~g} / \mathrm{cm}^{3}$. This wood species was selected for the regular morphology of its anatomical structure [20]. Ultrathin wood laminae (UWL) with a width of $11 \mathrm{~cm}$ and a thickness of about $150 \mu \mathrm{m}$ (see Figure 1a) were prepared at the CNR Ivalsa Institute (San Michele all'Adige, Italy), cutting them from beech boards conditioned at $23{ }^{\circ} \mathrm{C}$ and $\mathrm{RH}=60 \%$ by using a Marunaka Super Meca-s planer, supplied by Marunaka Tekkosho Inc. (Shizuoka, Japan).

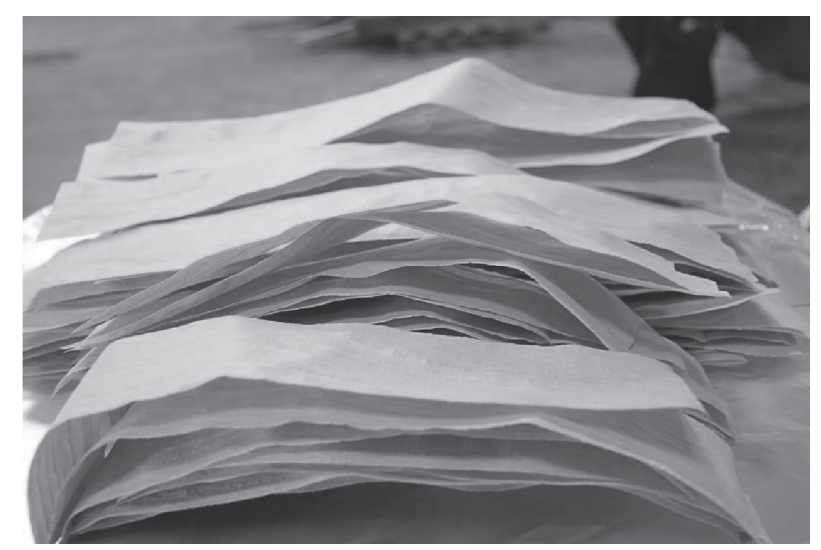

(a)

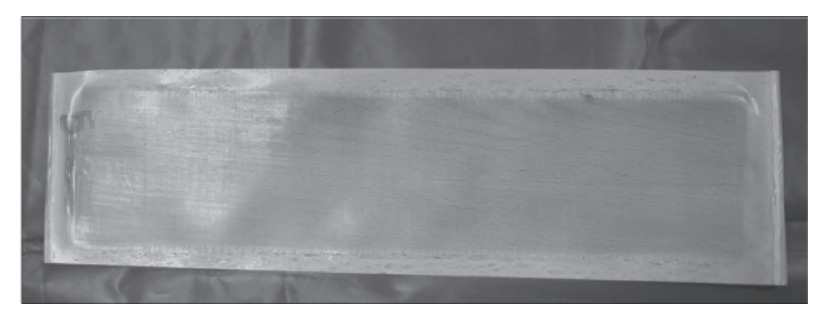

(b)

Figure 1 Representative image of (a) beech wood laminae and (b) CU_fk composite laminate. 
Table 1 Lamination sequence of the investigated composites.

\begin{tabular}{|l|c|c|c|c|}
\hline Sample & Matrix & N sheets & Stacking sequence & Thickness (mm) \\
\hline CU_fk & Mater $\mathrm{Bi}^{\circledR} \mathrm{Kf02b}$ & 5 & {$[0 / 0 / 0 / 0 / 0]$} & 0.57 \\
\hline CU_fc & Mater $\mathrm{Bi}^{\circledR} \mathrm{Cf51b}$ & 5 & {$[0 / 0 / 0 / 0 / 0]$} & 0.57 \\
\hline CB_fk & Mater $\mathrm{Bi}^{\circledR} \mathrm{Kf02b}$ & 4 & {$[0 / 90 / 90 / 0]$} & 0.63 \\
\hline
\end{tabular}

\subsection{Samples Preparation}

Before being used, wood laminae were dried at $80{ }^{\circ} \mathrm{C}$ for 24 hours. Laminates were prepared through a hand lay-up process followed by a hot-pressing step. Thermoplastic starch sheets were alternated with wood laminae according to a predetermined stacking sequence, and the resulting laminae were then pressed in a Carver press at $140{ }^{\circ} \mathrm{C}$ for 10 minutes under a pressure of 3.8 MPa. With this procedure, unidirectional biodegradable laminates were prepared by using two different TPS matrices (see Figure 1b). Moreover, balanced bidirectional composite laminates were prepared by using Mater-Bi K02b matrix. Table 1 summarizes the list of the prepared laminates. Unidirectional wood laminae were denoted as UWL, while thermoplastic starch matrices were designed as $\mathrm{Cf} 51 \mathrm{~b}$ and $\mathrm{Kf0} 0 \mathrm{~b}$, respectively.

It is important to underline that the utilization of ultrathin wood laminae cut from massive wood through a special planer implies that only reinforcing laminae with limited dimension can be produced. On the contrary, thermoplastic starch is available in big rolls. It is therefore clear that only a discontinuous process can be utilized to prepare this kind of laminates. The only way to increase the productivity of the presented system could be to introduce an automatic lamination machine. Thanks to optical sensors, it could be possible to select the orientation of the wood laminae and to quickly perform the stacking operations, prior to the final pressing of the material.

\subsection{Testing Techniques}

Field emission scanning electron microscopy (FESEM) images were acquired through a Zeiss Supra 40 microscope at the Biotech Center of the University of Trento (Italy). Samples were cryofractured in liquid nitrogen and laterally covered with a silver paint in order to render them electrically conductive.

Differential scanning calorimetry (DSC) measurements were carried out with a Mettler DSC30 machine under a nitrogen flow of $100 \mathrm{ml} / \mathrm{min}$. Samples were tested from $-100{ }^{\circ} \mathrm{C}$ to $200{ }^{\circ} \mathrm{C}$ at a heating rate of $10{ }^{\circ} \mathrm{C} / \mathrm{min}$ (first heating), then cooled down from $200{ }^{\circ} \mathrm{C}$ to $-100{ }^{\circ} \mathrm{C}$ at a rate of $-10{ }^{\circ} \mathrm{C} / \mathrm{min}$ (cooling) and re-heated at the same rate from $-100{ }^{\circ} \mathrm{C}$ to $200{ }^{\circ} \mathrm{C}$ (second heating).
Thermogravimetric analysis (TGA) was carried out by using a Mettler TG50 machine, in a temperature interval from $30^{\circ} \mathrm{C}$ up to $700{ }^{\circ} \mathrm{C}$ at $10^{\circ} \mathrm{C} / \mathrm{min}$, under a nitrogen flow of $100 \mathrm{ml} / \mathrm{min}$.

Quasi-static tensile tests were conducted by using an Instron 4502 testing machine. The tests on polymer matrices were carried out according to ASTM D882 standard. Tensile tests for the evaluation of the elastic modulus (E) were carried out at a crosshead speed of $25 \mathrm{~mm} / \mathrm{min}$ on specimens $20 \mathrm{~mm}$ wide and with a gage length of $250 \mathrm{~mm}$, without using extensometers (the system compliance was experimentally determined and considered). Tensile tests for the evaluation of the stress at break $\left(\sigma_{b}\right)$ were carried out on samples $20 \mathrm{~mm}$ wide and with a gage length of $50 \mathrm{~mm}$. Even in this case no extensometer was used. At least five specimens were tested for each composition. Tensile tests on wood laminae (UWL) were performed on rectangular laminae $170 \mathrm{~mm}$ long and $10 \mathrm{~mm}$ wide (the nominal lamina thickness is about $150 \mu \mathrm{m}$ ) at a testing speed of $5 \mathrm{~mm} / \mathrm{min}$. Samples were tested applying wood tabs on the grips, with a gage length of $100 \mathrm{~mm}$. At least 5 specimens were tested for each sample. Quasi-static tensile tests on composite laminates were performed according to ASTM D3039 standard at $5 \mathrm{~mm} / \mathrm{min}$ on rectangular specimens $250 \mathrm{~mm}$ long and $15 \mathrm{~mm}$ wide, applying wood tabs (the resulting gage length was 160 $\mathrm{mm})$. Even in this case, 5 specimens were tested for each sample.

Interlaminar shear strength (ILSS) of composite laminates was determined through short beam shear strength (SBSS) tests, performed with an Instron 4502 machine following the ASTM D2344 standard. For these tests unidirectional composite laminates with 45 layers were prepared (width $10 \mathrm{~mm}$, thickness 4.5 $\mathrm{mm}$, span length $28 \mathrm{~mm}$ ) and tested at $1 \mathrm{~mm} / \mathrm{min}$. The interlaminar shear strength $(\tau)$ was evaluated according to the expression reported in Equation 1:

$$
\tau=\frac{3 F_{\max }}{4 w t}
$$

where $\mathrm{F}_{\max }$ is the maximum load registered during the test, $w$ is the sample width and $t$ is its thickness.

The density of the wood $\left(\rho_{\mathrm{f}}\right)$ of the polymer matrix $\left(\rho_{\mathrm{m}}\right)$ and of the composite laminate $\left(\rho_{\mathrm{c}}\right)$ was determined through an Accupyc helium pycnometer. It was 
therefore possible to determine the volumetric fraction of the constituents $\left(\mathrm{V}_{\mathrm{f}}, \mathrm{V}_{\mathrm{m}}\right)$ and their relative weight concentration $\left(\mathrm{W}_{\mathrm{f}}, \mathrm{W}_{\mathrm{m}}\right)$ according to Equations 2-5:

$$
\begin{gathered}
\rho_{c}=\rho_{f} \cdot V_{f}+\rho_{m} \cdot V_{m} \\
V_{f}=1-V_{m} \\
W_{f}=\frac{\rho_{f}}{\rho_{c}} \cdot\left(\frac{\rho_{c}-\rho_{m}}{\rho_{f}-\rho_{m}}\right) \\
W_{m}=1-W_{f}
\end{gathered}
$$

The thermal weldability of composite laminates was evaluated by single-lap shear tests performed according to ASTM D1002 standard. In these tests, two adherends constituted by composite laminates (width 25.4 $\mathrm{mm}$, gauge length $64 \mathrm{~mm}$ ) were partly overlapped and pressed at $75{ }^{\circ} \mathrm{C}$ applying a pressure of $3.8 \mathrm{MPa}$ for $10 \mathrm{~min}$. An overlapping area of $12.7 \times 25.4 \mathrm{~mm}^{2}$ was fixed, while the extension of the gripped area was 25.4 $\times 25.4 \mathrm{~mm}^{2}$. The total length of the samples was 190.5 $\mathrm{mm}$. Samples were tested by using an Instron 4502 tensile testing machine at $1.3 \mathrm{~mm} / \mathrm{min}$. The configuration of the experimental apparatus for these tests is represented in Figure 2a. In this way, the maximum shear strength $\left(\tau_{\max }\right)$ and the deformation at the maximum shear strength $\left(\tau_{\max }\right)$ were determined.

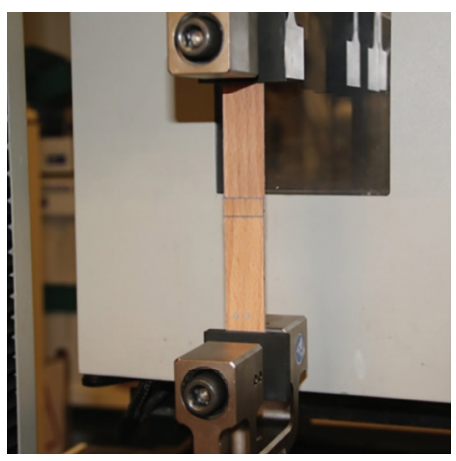

(a)

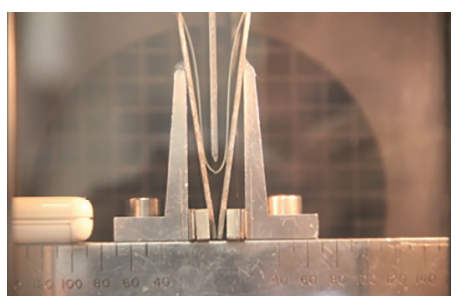

(b)

Figure 2 Experimental configuration for (a) thermal weldability tests and (b) thermal bending tests on CU_fk composite laminates.
Thermo-formability tests were evaluated by flexural test performed at various temperatures. According to the testing configuration depicted in Figure $2 b$, three point flexural tests were performed on rectangular samples $180 \mathrm{~mm}$ long and $20 \mathrm{~mm}$ wide, at a crosshead speed of $10 \mathrm{~mm} / \mathrm{min}$. The tests were performed at different temperatures (from $25^{\circ} \mathrm{C}$ to $75^{\circ} \mathrm{C}$ ), and through a camera the bending radius at different testing times was recorded. In this way, the critical bending radius $\left(R_{c}\right)$ at which delamination of composite samples occurred was determined.

\section{RESULTS AND DISCUSSION}

\subsection{Characterization of the Constituents}

In Figure 3a and Figure 3b, FESEM micrographs of fracture surfaces of UWL cut in the transversal and longitudinal directions are respectively reported. Clearly visible in the longitudinal direction is the typical structure of the wood, with tracheids, wood fibers and vessels, while the parenchymal cells are less clearly visible. Tracheids and wood fibers have a mean diameter of about $10 \mu \mathrm{m}$, while wood vessels have a mean size of $40 \mu \mathrm{m}$. In the transversal section the presence of some tracheids in radial direction can be recognized. Such microstructure could suggest the possibility of a partial matrix penetration in the wood pores, thus originating a complex microstructure and resulting in materials with peculiar properties with respect to their constituents.

In order to optimize the processing conditions of these materials and to correlate the microstructural behavior with the properties of the resulting laminates, DSC tests were performed on both thermoplastic starch matrices. In Figure 4(a,b) DSC thermograms of $\mathrm{Cf} 51 \mathrm{~b}$ and $\mathrm{Kf02} \mathrm{b}$ samples, taken during the first and second heating stage, are respectively reported, while the most significant results are summarized in Table 2. It is interesting to note how the DSC thermogram of the Cf51b matrix in the first heating stage is characterized by the presence of two distinct melting points located at $66^{\circ} \mathrm{C}$ and $112{ }^{\circ} \mathrm{C}$, and of two $\mathrm{T}_{\mathrm{g}}$ signals at $-26{ }^{\circ} \mathrm{C}$ and $49{ }^{\circ} \mathrm{C}$. The presence of these transitions is due to the presence in the matrix of starch fractions having different molecular weight, or to the presence of an elastomeric phase at low $\mathrm{T}_{\mathrm{g}}$ in the compound. It is well known that starch is often blended with other polymer species in order to render the resulting compound more ductile $[10,14]$. The thermogram recorded in the second heating stage is quite similar to that measured in the first heating, except for the fact that the first melting signal at $66^{\circ} \mathrm{C}$ disappears. As far as the Kf02b matrix is concerned (Figure $4 \mathrm{~b}$ ), three distinct melting signals at $69^{\circ} \mathrm{C}$ (more intense), 


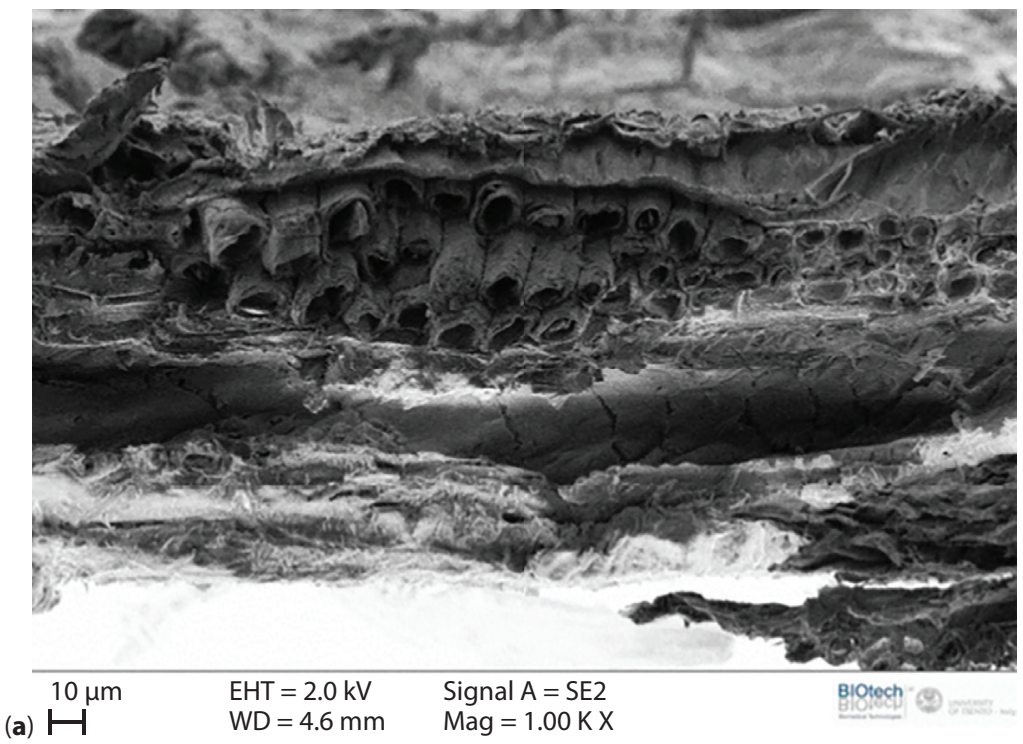

(a) $\mapsto$ $\mathrm{WD}=4.6 \mathrm{~mm} \quad \mathrm{Mag}=1.00 \mathrm{KX}$

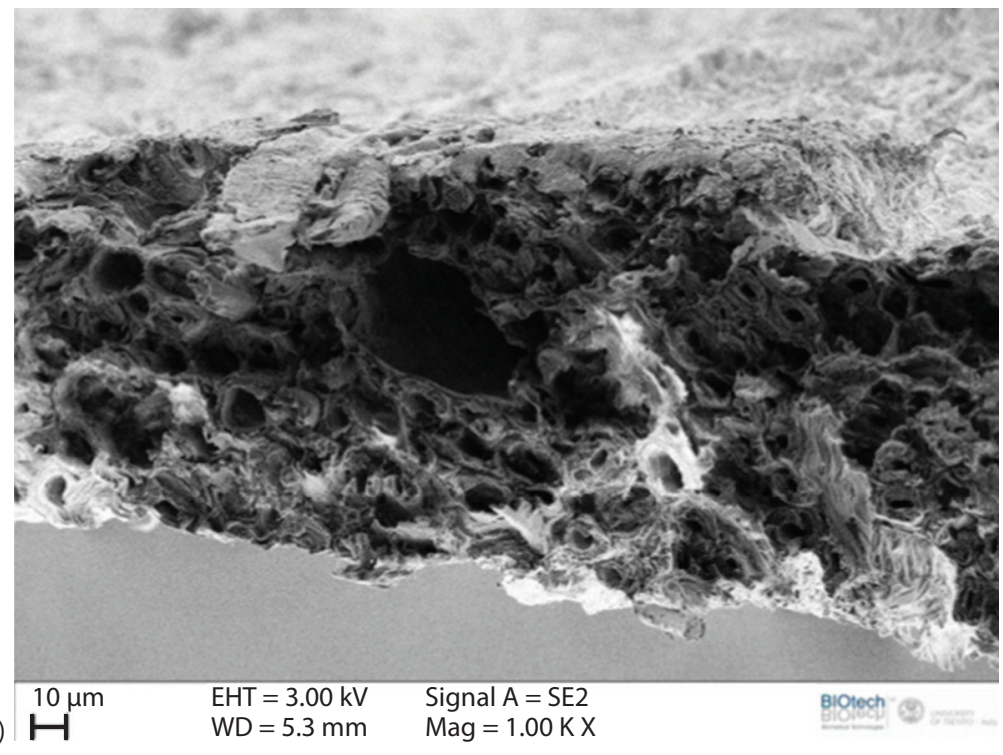

Figure 3 FESEM images of (a) longitudinal and (b) transversal cross sections of the UWL samples.

$124^{\circ} \mathrm{C}$ and $158^{\circ} \mathrm{C}$ can be clearly detected. A $\mathrm{T}_{\mathrm{g}}$ can be detected at low temperature $\left(-23^{\circ} \mathrm{C}\right)$, probably due to the presence of an elastomeric phase at low concentration within the material. Even in this case, the thermogram in the second heating stage is very similar to that detected in the first scan. At a general level, it can therefore be concluded that a processing temperature of $140{ }^{\circ} \mathrm{C}$ could be suitable to prepare composite laminates. In fact, at this temperature, both matrices are in the molten state and the risk of thermal degradation of wood laminae is limited. It is important to underline that a more detailed analysis of the thermal behavior of these materials should be required to reach a deeper comprehension of the melting/crystallization properties of the investigated matrices. However, this analysis, even if interesting from an experimental point of view, is out of the main scope of the present paper, and could be reported in future papers on these systems.

In order to evaluate the thermal degradation resistance of the constituents, TGA analysis was performed on ultrathin wood laminae and on both matrices (see Figure $5 \mathrm{a}-\mathrm{c}$ ). It is interesting to note that UWL presents a first mass drop of about $10 \%$ at around $100{ }^{\circ} \mathrm{C}$, due to the presence of absorbed water, while the thermal degradation of the wood starts at temperatures above $250{ }^{\circ} \mathrm{C}$ (Figure 5a). It is important to remember that wood laminae were carefully dried before being coupled with starch-based matrices, in order to minimize degradation by hydrolysis of the matrix during the subsequent hot-pressing operations and the formation of voids due to vapor bubbles. Thermoplastic starch matrices present a similar thermal degradation 

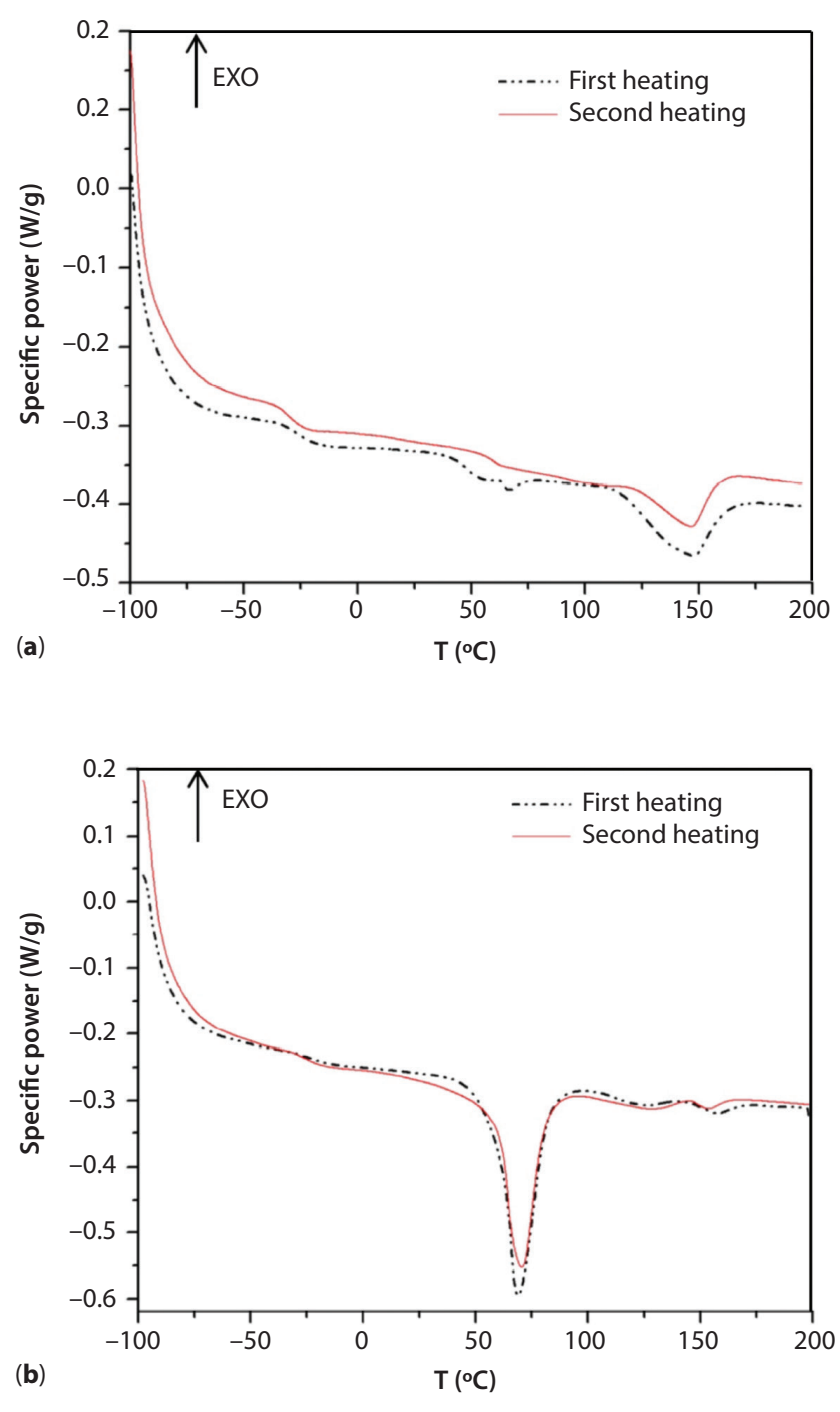

Figure 4 DSC thermograms of (a) Cf51b and (b) Kf02b samples (first and second heating stage).

Table 2 DSC results of thermoplastic starch matrices.

\begin{tabular}{|c|c|c|c|c|}
\hline Sample & $\mathrm{T}_{\mathrm{g} 1}\left({ }^{\circ} \mathrm{C}\right)$ & $\mathrm{T}_{\mathrm{m} 1}\left({ }^{\circ} \mathrm{C}\right)$ & $\mathrm{T}_{\mathrm{g} 2}\left({ }^{\circ} \mathrm{C}\right)$ & $\mathrm{T}_{\mathrm{m} 2}\left({ }^{\circ} \mathrm{C}\right)$ \\
\hline \multirow[t]{2}{*}{ Cf51b } & -26.3 & 66.3 & -28.2 & 146.9 \\
\hline & 48.9 & 112.3 & 59.9 & - \\
\hline \multirow[t]{3}{*}{$\mathrm{Kf02b}$} & -23.4 & 69.1 & -24.1 & 70.9 \\
\hline & - & 123.9 & - & 128.2 \\
\hline & - & 157.7 & - & 154.1 \\
\hline
\end{tabular}

behavior. In this case no water loss was detected at 100 ${ }^{\circ} \mathrm{C}$, while thermal degradation is appreciable at temperatures above $300{ }^{\circ} \mathrm{C}$ (Figure $5 \mathrm{~b}-\mathrm{c}$ ). It can therefore be concluded that both constituents present a thermal stability compatible with the processing of composite laminates at $140{ }^{\circ} \mathrm{C}$.
In Figure 6a-c representative stress-strain curves obtained from quasi-static tensile tests of UWL and starch-based matrices are reported, while the most important mechanical parameters are summarized in Table 3. UWL presents a linear behavior in the first part of the stress-strain curve, followed by a transition zone with a lower slope (Figure 6a). The deformation at break is rather limited (less than 6\%). On the other hand, the tensile behavior of starch matrices is typical of a thermoplastic material with elevated ductility. The elastic region is followed by a zero-slope point conventionally representing the yield point. After yielding, a very large plastic strain is produced, with deformation at break higher than $350 \%$ (Figure $6 \mathrm{~b}-\mathrm{c}$ ). From the results reported in Table 3, it is clear that the measured stiffness and strength values of the wood thin laminae are considerably lower than those reported for bulk wood. In fact, a flexural modulus of $14.5 \mathrm{GPa}$ and an ultimate flexural stress of $120 \mathrm{MPa}$ is reported for massive beech [20]. This discrepancy is probably due to the fact that cutting ultrathin wood sheets implies that the original cellular morphology of the wood is largely destroyed, and the stiffness of the pristine bulk material is impaired. The tensile properties of starch resins are very close to those reported in the literature for similar materials [25].

\subsection{Characterization of Laminates}

Considering that the microstructural features of the prepared laminates are strongly correlated with their thermo-mechanical behavior, FESEM images of the fracture surface of the prepared laminates were taken. In Figure 7a,b, FESEM micrographs of the fracture surfaces of CU_fk laminate, taken in longitudinal direction and in transversal direction, are respectively shown. From these micrographs, it is clear that part of the starch-based matrix penetrated the wood structure, partially filling the voids inside the wood fibers and the tracheids. Also, the radial tracheids seem to be partially filled by the resin. It appears that the greatest part of the polymer matrix penetrated the wood porosity, and only a small fraction of the polymer remained in the interlayer region. A similar morphology was already observed in similar composites obtained by using a poly(vinyl-alcohol) matrix [23]. In that work, it was demonstrated how the PVOH solution was able to penetrate the wood structure, filling the pores of the wood reinforcements. In the present paper, it has also been demonstrated that thermoplastic starch, if processed above its melting temperature, is able to enter wood porosity. It is therefore very likely that such microstructure could strongly influence the tensile behavior of the resulting laminates. 

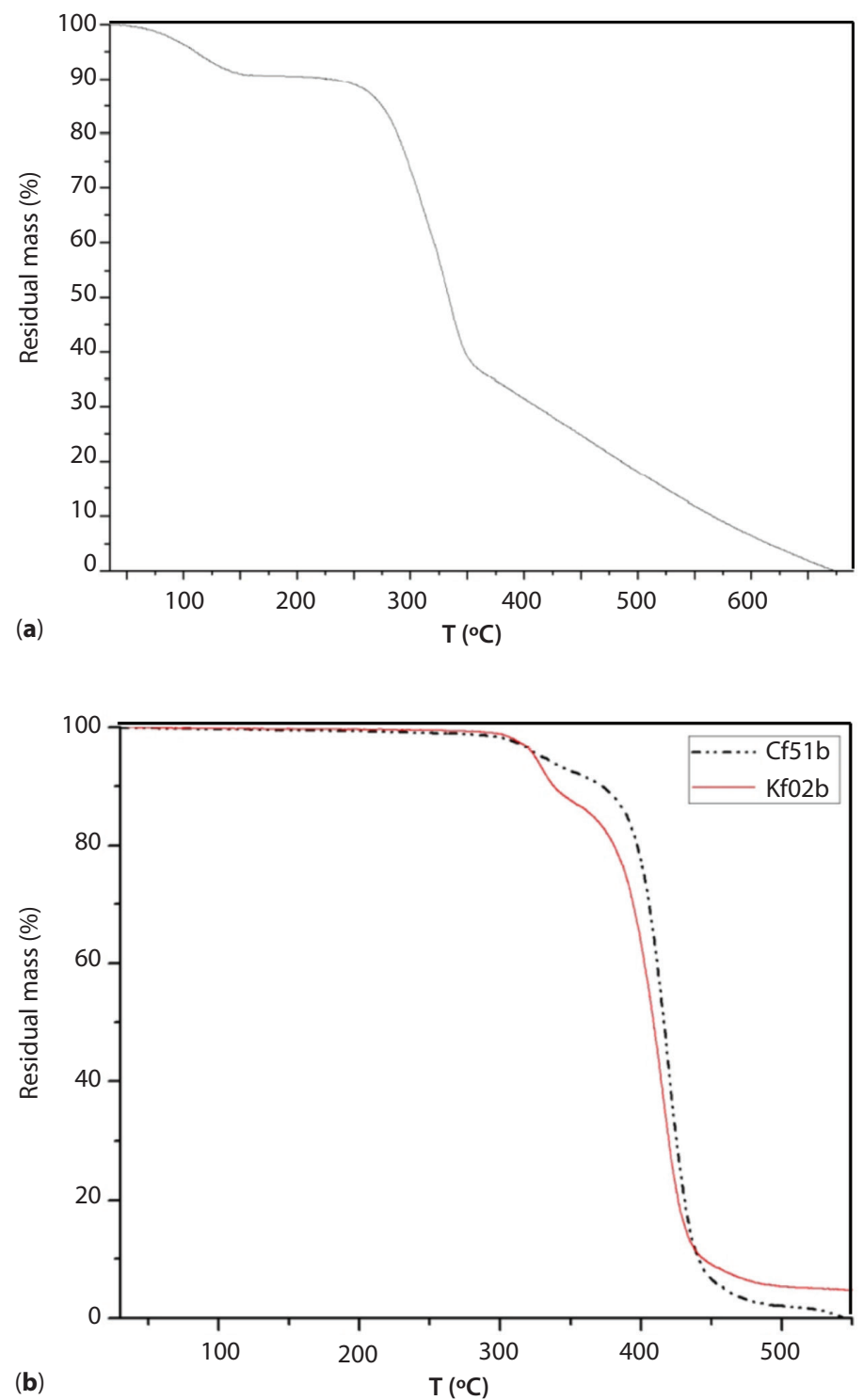

Figure 5 Thermogravimetric analysis of (a) UWL and (b) thermoplastic starch matrices.

In Table 4 the results of the density measurements on the prepared samples, with the weight and volume fractions of the constituents in the CU_fk laminate, are summarized. For this laminate, a density of $1.24 \pm 0.01$ $\mathrm{g} / \mathrm{cm}^{3}$ was determined, while a density of $1.48 \mathrm{~g} / \mathrm{cm}^{3}$ was measured for the wood laminae (density values of 1.18 and $1.19 \mathrm{~g} / \mathrm{cm}^{3}$, as taken from the producer datasheet, were considered for $\mathrm{Cf} 51 \mathrm{~b}$ and for $\mathrm{Kf02b}$ matrices, respectively). It is important to underline that in the case of wood laminae a real density value was determined with pycnometric measurements (corresponding to the density of hemicellulose and lignin), because the probe gas (helium) certainly penetrates the macroscopic pores of beech wood. Applying Equations (1-4), it can be concluded that the final concentration of the polymeric matrix in the composite is very high $\left(\mathrm{V}_{\mathrm{m}}=0.80\right.$ and $\left.\mathrm{W}_{\mathrm{m}}=0.76\right)$. The concentration of the reinforcement $\left(\mathrm{V}_{\mathrm{f}}=0.20\right.$ and $\left.\mathrm{W}_{\mathrm{f}}=0.24\right)$ is thus lower than that traditionally utilized for composite laminates.

It is now important to evaluate how the observed microstructure influences the tensile behavior of the resulting laminates. In Figure 8a, a representative stress-strain curve from quasi-static tensile tests on CU_fk composite laminate is reported, while in Table 5 the most important mechanical properties are summarized. It is clear that the tensile properties $\left(E, \sigma_{b}\right)$ of the unidirectional laminates are very similar, because the mechanical behavior of fiber reinforced polymer is mostly influenced by the properties of the reinforcement. Moreover, it results in the properties of the bidirectional laminate (CB_fk) being lower than those of 

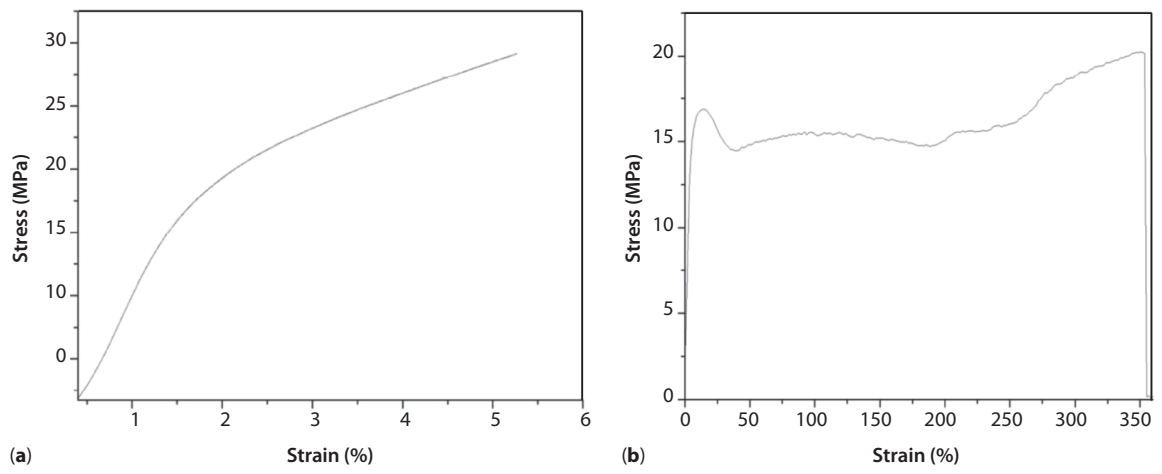

(a)

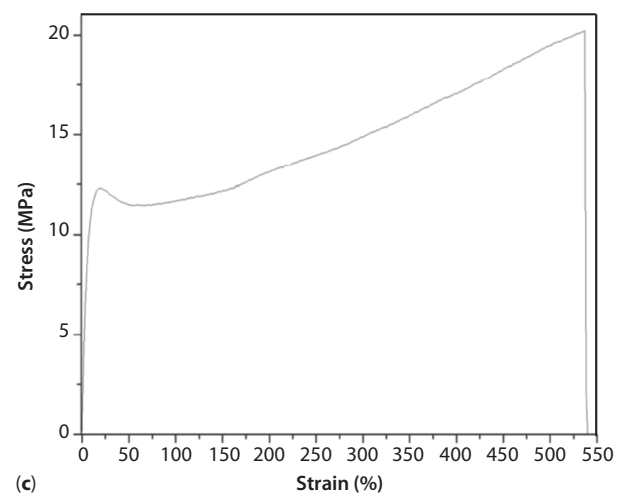

Figure 6 Representative stress-strain curves of (a) UWL in longitudinal direction, (b) Kf02b and (c) Cf51b matrices.

Table 3 Quasi-static mechanical properties of UWL and thermoplastic starch matrices.

\begin{tabular}{|l|c|c|}
\hline Sample & E (MPa) & $\sigma_{\mathbf{b}}(\mathbf{M P a})$ \\
\hline UWL & $2282 \pm 230$ & $45 \pm 19$ \\
\hline Cf51b & $200 \pm 17$ & $19 \pm 3$ \\
\hline Kf02b & $530 \pm 21$ & $18 \pm 3$ \\
\hline
\end{tabular}

the corresponding unidirectional composite. This is due to the orthotropic nature of the wood reinforcement (i.e., the transversal properties of the wood are considerably lower than the longitudinal ones). It is interesting to compare the elastic modulus of the CU_fk laminate (5630 MPa) with the theoretical value obtained applying the traditional rule of mixture of unidirectional laminates (1917 MPa). It is clear that the experimental value of the modulus is considerably higher than that coming from the theoretical predictions. Also, the tensile strength of this laminate (i.e., $76 \mathrm{MPa}$ ) is higher than that of its constituents. The obtained results are thus completely opposite to those predicted by using the rule of mixture traditionally adopted to predict the elastic constants of composite materials. According to FESEM micrographs, it is evident that the matrix interpenetration within wood laminae induces the occlusion of the wood porosity. In these conditions, the loss of the mechanical properties of the original reinforcing phase due to the ultrathin cut is partially recovered by the void filling performed by the starch resin. A similar result was also obtained by using a PVOH matrix [23].

It is now interesting to analyze the data regarding the interlaminar shear strength of the prepared composite laminates. In Figure $8 \mathrm{~b}$ a representative loaddisplacement curve from short beam shear tests on CU_fk composite laminate is reported, while in Table 5 the interlaminar shear strength values are reported. It can be concluded that the reported $\tau$ values for the tested unidirectional composites are quite similar. Even if the interlaminar shear strength of thermoplastic composite laminates is generally lower than that of thermosetting resin-based laminates [26], the obtained values are rather low if compared to the values commonly reported in the literature for thermoplastic composites. A modification of the processing conditions (pressing time and/or temperature) or the surface activation of the wood laminae or of the starch sheets could represent a viable solution to improve the interfacial adhesion conditions of these laminates.

Finally, the workability of the prepared composites was evaluated through thermal weldability and thermo-formability tests. In Table 6 the results of these tests are summarized. It is interesting to note how the maximum shear strength $\left(\tau_{\max }\right)$ and the relative critical deformation values $\left(\varepsilon_{\max }\right)$ at $65^{\circ} \mathrm{C}$ are lower than those measured at $85^{\circ} \mathrm{C}$. These results could be explained considering that the DSC test reported for the Kf02b matrix showed a first melting temperature peak $\left(\mathrm{T}_{\mathrm{m} 1}\right)$ 


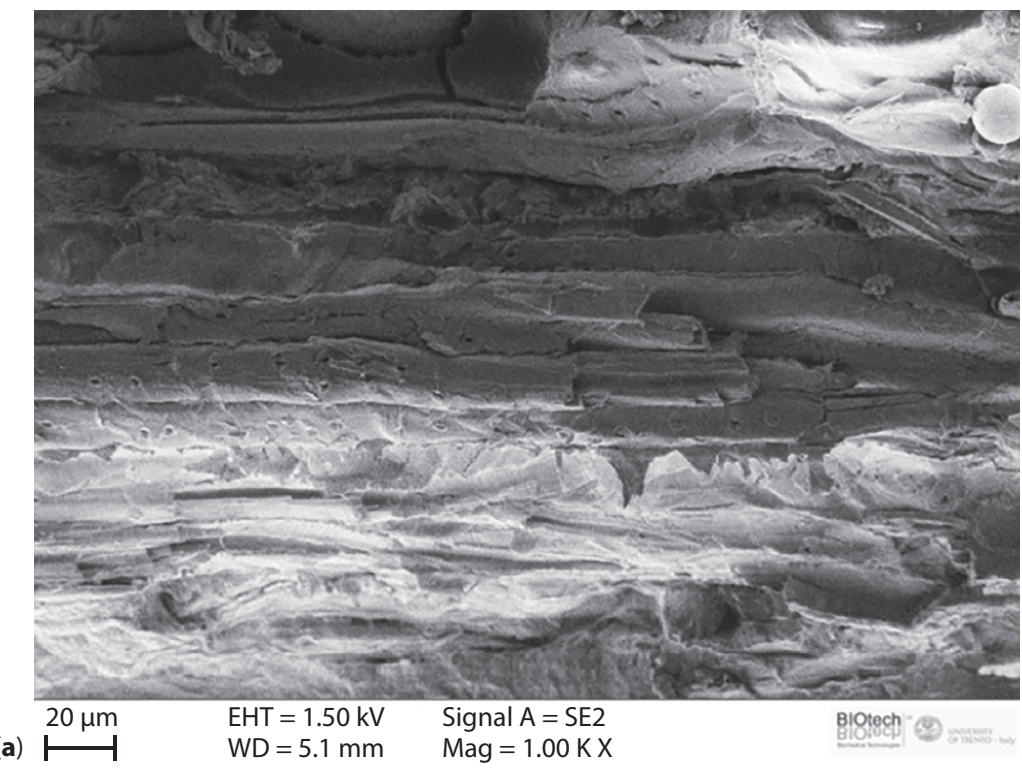

(a)

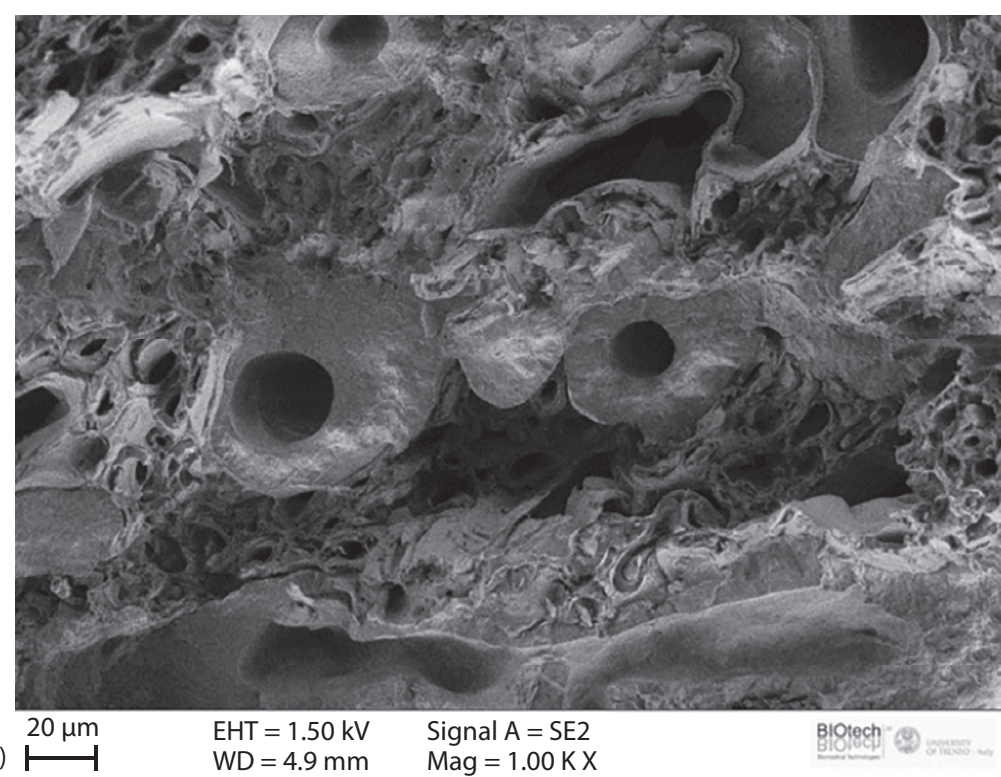

Figure 7 FESEM images of the fracture surfaces of CU_fk laminate: (a) Longitudinal direction and (b) transversal direction.

Table 4 Volumetric/weight fractions of the constituents of the CU_fk composite laminate.

\begin{tabular}{|l|c|c|}
\hline Constituent & $\mathbf{f}_{\mathbf{v}}$ & $\mathbf{f}_{\mathbf{m}}$ \\
\hline UWL & 0.20 & 0.24 \\
\hline Kf02b & 0.80 & 0.76 \\
\hline
\end{tabular}

at $69{ }^{\circ} \mathrm{C}$. Therefore, a better welding of the adherends can be obtained above the melting temperature of the matrix. Thermo-formability tests are important to evaluate the thermoforming capability of the prepared laminates. As reported in Table 6, the critical bending radius $\left(R_{c}\right)$ decreases with the testing temperature, and the best results can be obtained at $75{ }^{\circ} \mathrm{C}$ (above the melting temperature of the matrix). At a general level, it can be concluded that the prepared laminates present interesting workability conditions, and thus can be effectively applied for the preparation of thermoformable sheets for packaging applications.

\section{CONCLUSIONS}

Ultrathin beech laminae were cut through an innovative liner and used to prepare fully biodegradable laminates through a hot-pressing process, by using two different thermoplastic starch-based (TPS) matrices. After a detailed characterization of the constituents, the most important physical properties of unidirectional and bidirectional laminates were investigated. 

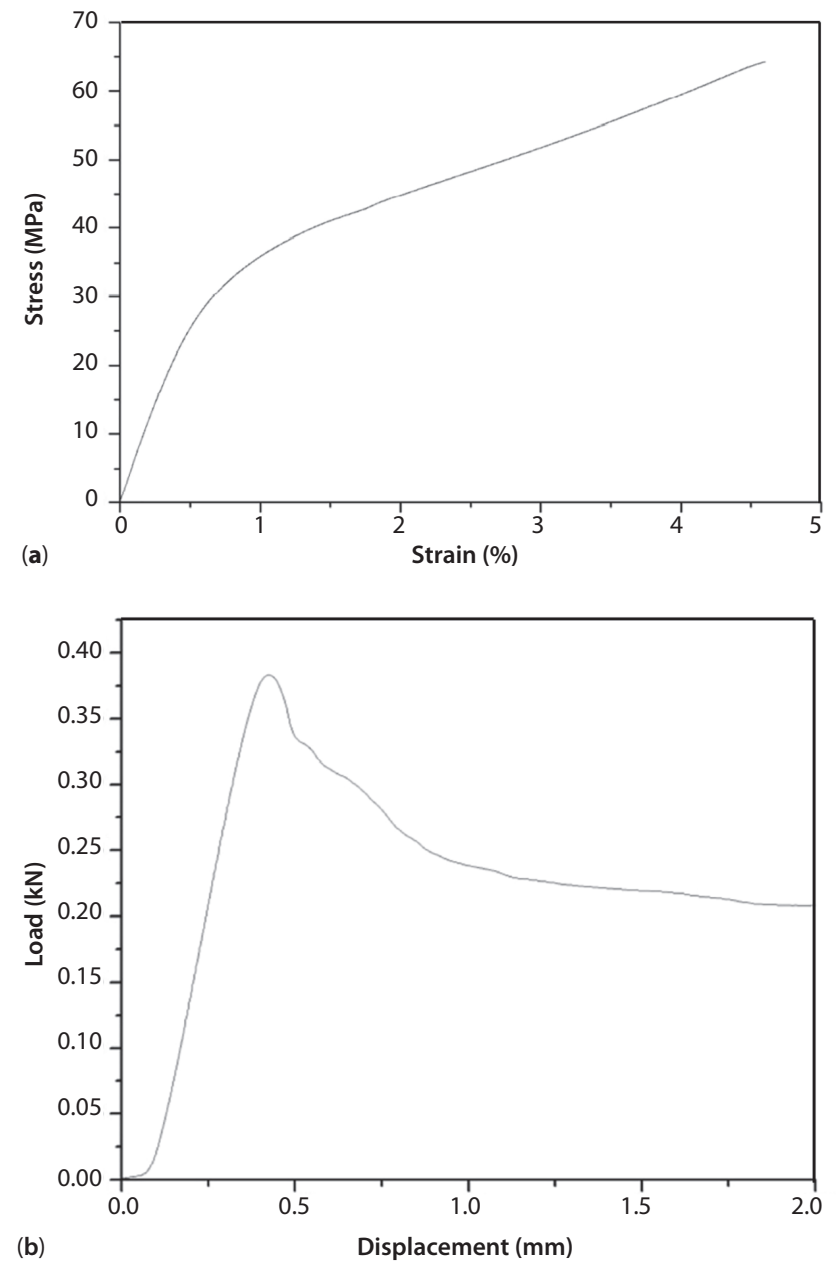

Figure 8 (a) Representative stress-strain curves from quasistatic tensile tests and (b) representative load-displacement curve from short beam tests on CU_fk composite laminate.

Table 5 Quasi-static tensile properties and interlaminar strength of the prepared composite laminates.

\begin{tabular}{|l|c|c|c|}
\hline Sample & $\mathbf{E}(\mathbf{M P a})$ & $\sigma_{\mathbf{b}}(\mathbf{M P a})$ & $\boldsymbol{\tau} \mathbf{( M P a )}$ \\
\hline CU_fk & $5630 \pm 115$ & $76 \pm 2$ & $6.96 \pm 0.34$ \\
\hline CU_fc & $5720 \pm 140$ & $61 \pm 7$ & $5.17 \pm 0.45$ \\
\hline CB_fk & $3540 \pm 215$ & $31 \pm 1$ & - \\
\hline
\end{tabular}

The resulting materials presented a peculiar microstructure, in which the original porosity of the wood laminae was almost entirely occluded by the polymer matrix. The obtained microstructure strongly influenced the mechanical behavior of the resulting laminates. Even if the ultrathin laminae manifested mechanical properties lower than that of the corresponding massive wood, the occlusion of macroscopic porosity caused by matrix penetration led to fully biodegradable composites having stiffness and strength values considerably higher than those of
Table 6 Evaluation of the workability of the CU_fk composite laminate.

\begin{tabular}{|l|c|}
\hline$\tau_{\max }$ at $85^{\circ} \mathrm{C}(\mathrm{MPa})$ & $3.4 \pm 0.4$ \\
\hline$\varepsilon_{\max }$ at $85^{\circ} \mathrm{C}(\%)$ & $2.3 \pm 0.7$ \\
\hline$\tau_{\max }$ at $65^{\circ} \mathrm{C}(\mathrm{MPa})$ & $2.5 \pm 0.7$ \\
\hline$\varepsilon_{\max }$ at $65^{\circ} \mathrm{C}(\%)$ & $1.5 \pm 0.9$ \\
\hline$R_{\mathrm{c}}$ at $25^{\circ} \mathrm{C}(\mathrm{mm})$ & $2.76 \pm 0.41$ \\
\hline$R_{\mathrm{c}}$ at $40^{\circ} \mathrm{C}(\mathrm{mm})$ & $2.85 \pm 0.43$ \\
\hline$R_{\mathrm{c}}$ at $55^{\circ} \mathrm{C}(\mathrm{mm})$ & $2.31 \pm 0.28$ \\
\hline$R_{c}$ at $75^{\circ} \mathrm{C}(\mathrm{mm})$ & $1.96 \pm 0.58$ \\
\hline
\end{tabular}

$\tau_{\max }=$ maximum shear stress

$\varepsilon_{\max }=$ maximum deformation

$\mathrm{R}_{\mathrm{c}}=$ critical bending radius

their constituents. The prepared laminates were characterized by rather limited interlaminar shear strength values, and further efforts will be made in the future to improve their interfacial adhesion conditions. Nevertheless, thermal welding and thermo-forming tests demonstrated how the prepared laminates possessed interesting workability properties, especially if they are processed above the melting temperature of the matrix.

\section{ACKNOWLEDGMENTS}

Mr. Francesco Giachi is gratefully acknowledged for his support of the experimental work. This work has been conducted within the project "Preparation and characterization of biodegradable wood-based composites" financed by the Fondazione Cassa di Risparmio di Trento e Rovereto.

\section{REFERENCES}

1. D. Gay, S.V. Hoa, and S.W. Tsai, Composite Materials: Design and Applications, CRC Press, Boca Raton, FL, USA (2003).

2. A. Pegoretti, Expressing polymers for a sustainable development. Express Polym. Lett. 11(11), 852-852 (2017).

3. J.M. Henshaw, W. Han, and A.D. Owens, An overview of recycling issues for composite materials. J. Thermoplast. Compos. Mater. 9(1), 4-20 (1996).

4. C.-S. Wu, Renewable resource-based composites of recycled natural fibers and maleated polylactide bioplastic: Characterization and biodegradability. Polym. Degrad. Stab. 94(7), 1076-1084 (2009).

5. M. García, I. Garmendia, and J. García, Influence of natural fiber type in eco-composites. J. Appl. Polym. Sci. 107(5), 2994-3004 (2008).

6. A. Iwatake, M. Nogi, and H. Yano, Cellulose nanofiberreinforced polylactic acid. Compos. Sci. Technol. 68(9), 2103-2106 (2008).

7. T. Kunanopparat, P. Menut, M. Morel, and S. Guilbert, Reinforcement of plasticized wheat gluten with natural 
fibers: From mechanical improvement to deplasticizing effect. Compos. Part A Appl. Sci. Manuf. 39(5), 777785 (2008).

8. S. Houshyar and R.A. Shanks, Morphology, thermal and mechanical properties of poly(propylene) fibrematrix composites. Macromol. Mater. Eng. 288(8), 599606 (2003).

9. T.Y. Bogracheva, Y.L. Wang, T.L. Wang, and C.L. Hedley, Structural studies of starches with different water contents. Biopolymers 64(5), 268-281 (2002).

10. A. Mohammadi Nafchi, M. Moradpour, M. Saeidi, and A.K. Alias, Thermoplastic starches: Properties, challenges, and prospects. Starch - Stärke 65(1-2), 61-72 (2013).

11. A. Ayucitra, Preparation and characterisation of acetylated corn starches. Int. J. Chem. Eng. Appl. 3(3), 156-159 (2012).

12. H. Chi, K. Xu, X. Wua, Q. Chen, D. Xue, C. Song, W. Zhang, and P. Wang, Effect of acetylation on the properties of corn starch. Food Chem. 106, 923-928 (2008).

13. L. Averous, N. Fauconnier, L. Moro, and C. Fringant, Blends of thermoplastic starch and polyesteramide: Processing and properties. J. Appl. Polym. Sci. 76(7), 1117-1128 (2000).

14. C. Bastioli, Properties and application of mater-Bi starch-based materials. Polym. Degrad. Stab. 59, 263-272 (1998).

15. J. Lorcks, Properties and applications of compostable starch-based plastic material. Polym. Degrad. Stab. 59, 245-249 (1998).

16. G. Cecchini, L'identificazione dei legnami, Hoepli, Milan, Italy (1951).
17. G. Tsoumis, Science and Technology of Wood: Structure, Properties, Utilization, Van Nostrand Reinhold, New York, USA (1991).

18. H.A. Core, W.A. Coté, and A.C. Day, Wood: Structure and Identification, 2nd ed., Syracuse University Press, USA (1979).

19. D.W. Green, J.E. Winandy, and D.E. Kretschmann, Mechanical properties of wood, in Wood HandbookWood as an Engineering Material, F.P. Laboratory (Ed.), U.S. Department of Agriculture, Forest Service, Forest Products Laboratory (1999).

20. G. Giordano, Tecnologia del legno. La materia prima, vol. 1, UTET, Torino (1981).

21. K. Oksman and M. Sain, Wood-Polymer Composites, Woodhead Publishing Materials, Cambridge, England (2008).

22. P. Srimalanon, W. Yamsaengsung, A. Kositchaiyong, E. Wimolmala, K. Isarangkura, and N. Sombatsompop, Effects of UV-accelerated weathering and natural weathering conditions on anti-fungal efficacy of wood/PVC composites doped with propylene glycolbased HPQM. Express Polym. Lett. 10(4), 289-301 (2016).

23. A. Dorigato, M. Negri, and A. Pegoretti, Ultrathin wood laminae-polyvinyl alcohol biodegradable composites. Polym. Compos. (In Press).

24. A. Dorigato and A. Pegoretti, Biodegradable singlepolymer composites from polyvinyl alcohol. Colloid Polym. Sci. 290, 359-370 (2012).

25. J.E. Mark, Polymer Data Handbook, Oxford University Press, Oxford (1999).

26. S. Beland, High Performance Thermoplastic Resins and Their Composites, William Andrew, New Jersey, USA (2012). 